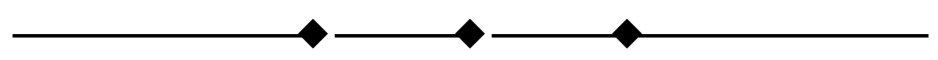

\title{
Editorial
}

\section{'Internationalisation' and the social sciences}

We hear ever more about the internationalisation of higher education. As U.K. universities become increasingly exposed to the vagaries of international student demand, administrators are scrambling to develop 'internationalisation' strategies, whilst academics are being encouraged to incorporate 'international perspectives' into their curricula. Even the U.K.'s Centre for Learning and Teaching Sociology, Anthropology and Politics (C-SAP) has a strategic aim to promote 'best practice in the internationalisation of the student learning experience'. It sounds impressive, but what does it mean in practice? Internationalisation has become a buzzword that everyone can use without having to agree on what they mean. The word's descriptive malleability is its analytical downfall.

Like any such portmanteau concept, 'internationalisation' decants an assortment of older discourses and debates into a shiny new policy container. It gets used to justify anything from institutional restructuring to six-figure salaries for 'top' academic researchers. The histories and politics contained within the term are complex and contradictory. An example of such politics is the economic imperative driving decisions in all universities. Is talk of internationalism just a brave attempt to give a moral valence to the less palatable logic of global capital? Another is the neo-liberal political discourse advocating managerial and governance reforms across whole higher education sectors. The rationale is that they will enable institutions to compete in a global knowledge economy. The reality may be to make institutions increasingly vulnerable to market 'turbulence', as the meteorological euphemism puts it. 
Reforms are also linked into an international pressure for policy convergence, whether as part of the Bologna process or the result of Organisation for Economic Co-operation and Development (OECD) recommendations. Last but not least is the political sleight of hand by which 'international' definitions of research excellence are defined by journal citation indices, compiled by a small team of mostly English-language researchers working within Thompson Scientific's research department in an office in Philadelphia.

Accompanying the policymakers' fascination with internationalisation is a growing academic literature on the topic. The literature tends to fall into two broad groups. One group seeks to try and make sense of the different uses of the term and its relationship to globalisation (e.g. Van der Wende 2001; Teichler 2004). This debate inevitably remains at a high level of generalisation. However, the dominant focus on the commercial aspects of internationalisation leads Teichler to ask whether less attention ought to be paid to 'turbo-capitalism' and more to the potential for 'global understanding'. The other broad grouping tends to focus on the challenges internationalisation poses for host institutions and their pedagogies (e.g. de Vita and Case 2003).

What is largely missing in this debate is close empirical attention to the way that higher education policy reforms, developed in response to the challenges of 'internationalisation', get interpreted and translated within particular national or institutional contexts. It is this gap that this issue of LATISS sets out to tackle. Drawing on the critical insights and ethnographic sensitivities of the social sciences, the papers collectively focus on the national and regional dimensions of this global higher education reform movement. They offer us a valuable archaeology of neo-liberal policy developments in Europe, East Asia and Africa, and draw attention to the impacts of these reforms on university life and academic practice.

The first paper, by Roger Goodman, presents the curious paradox of a liberalised Japanese higher education system, its numer- 
ous private universities caught between an over-achieving school system and a demanding employment culture. As a result, he suggests, higher education has been given perhaps too much autonomy - leading to a strong anti-reform discourse within universities and, less palatably, an 'inherent feudalism'. Combining the effects of a major demographic contraction in the numbers of undergraduate students with the government's more selective approach to funding, the future for many private universities looks grim.

The next paper, by Susan Wright and Jakob Williams Ørberg traces the tangled history of Danish university reforms, from the 1980s to the present day, exploring the implications of a 2003 government statute that declared universities no longer to be state institutions, but rather 'self-owning institutions'. At first sight this seems to be a move to enable greater autonomy. Yet the authors show that it leaves universities with responsibility for their own finances, but dependent on state contracts and the whole apparatus of administrative accounting that comes with it. The authors conclude that the Danish model combines the 'worst of both the free trade and the modernising state models of autonomy'.

The third, by Yann Lebeau and David Mills, explores the history of higher education reforms in sub-Saharan Africa since the colonial period. They point to the influence of international organisations - notably the World Bank and the U.S. philanthropic foundations - over the development both of African higher education reforms and the ways in which social science researchers have analysed these reforms. They argue that attempts by international donors to invigorate locally relevant research capacity are actually limiting the re-emergence of a critical scholarly autonomy. The promise to enact the 'transformation' of African universities remains largely rhetorical.

The final paper goes beyond reforms of particular higher education systems to look at the reforming role that the social 
sciences themselves could play. Davydd Greenwood and Morten Levin describe their role in facilitating an unusual action-research project, involving senior social science academics from Europe and America. Starting out with their concerns about the potential 'irrelevance' of the social science, the rolling series of U.S.European summits they convened led to productive dialogues with university administrators, a growing awareness of academic 'selfdomination', and the importance of redefining academic freedom for a new scholarly generation. Greenwood and Levin throw down a gauntlet to the social sciences. They raise 'cornerstone' issues for the future study of universities and ask, 'Why are so few social scientists studying universities as work organisations and cultural systems?' If you would like to respond to the issues Greenwood and Levin raise, please send your contribution (max. 2,000 words) to the editors (P.Welch@wlv.ac.uk).

What additional concerns might be raised if such an actionresearch project in future were to include representatives of the developing world? They might call for greater engagement and dialogue between different national academies, less use of Southern research 'partners' as consultants or research 'informants', and greater valuing of the skills and knowledges that international students bring to the university classroom. Funders could also, they might suggest, do more to support more genuinely collaborative North-South linkages, exchanges and fellowships, both for teaching and research. A more cosmopolitan geography of social science teaching, research and publication might then beckon. The tasks facing social scientists committed to institutional reform continues to lengthen.

Finally, what does this collection of articles tell us about the future of what Wallerstein (1999) memorably referred to as the 'world university system'? Will the politicians' discourse of competitive internationalisation be gradually replaced by a scholarly commitment to collaborative internationalism? But can such a 
vision be reconciled with an increasingly stratified system, growing competition for students and the disproportionate influence held by Anglophone journals, university presses and citation indices? Higher education is set to remain the best of worlds, and the worst of worlds.

\section{References}

De Vita, G. and Case, P. (2003) 'Rethinking the internationalisation agenda in UK higher education', Journal of Further and Higher Education 27(4): 383-98.

Teichler, U. (2004) 'The changing debate on internationalisation of higher education', Higher Education 48: 5-26.

Van der Wende, M. (2001) 'Internationalisation policies: about new trends and contrasting paradigms', Higher Education Policy 14: 249-59.

Wallerstein, I. (1999) The Social Sciences in the 21st Century, World Social Science Report, UNESCO.

David Mills, University of Oxford, U.K.

Email: david.mills@edstud.ox.ac.uk 